\title{
Biocatalytic Approaches to Optically Active $\beta$-Blockers
}

\author{
D. Żelaszczyk and K. Kieć-Kononowicz*
}

Department of Technology and Biotechnology of Drugs, Medical College, Jagiellonian University, Medyczna 9, 30-688 Kraków, Poland

\begin{abstract}
Beta-blockers are a very important group of drugs widely used for the treatment of cardiovascular diseases. All aryloxyaminopropanols are chiral and show different stereoselectivity in their pharmacodynamic and pharmacokinetic properties for each enantiomer. The more potent beta-adrenoceptor blocking activity is generally associated with $(S)$-enantiomers. Most beta-blocking agents are sold as racemates although $(R)$ enantiomers not only show in some cases lack of activity but might be responsible for undesirable effects.
\end{abstract}

Among reports on the direct enzymatic resolution of the most representative beta-blocker propranolol, the most interesting is $N$-acetylation method with commercially available lipases to yield $(S)-N$ acetylpropranolol. Another type of the one-step $(S)$-isomer biocatalytic preparation from racemic mixture of propranolol is the biodegradation with the fungus.

Biocatalytic methods of obtaining homochiral beta-blockers that are focused on production of versatile precursors are widely described in literature. The strategies based on the use of glycidol and derivatives as C-3 synthones have been shown to be extremely useful for the introduction of the 2-propanol chain on the aromatic system.

Halohydrins are the established intermediates in the preparation of optically active beta-blockers. Its resolution by esterhydrolases has been used as a standard alternative in preparation of the homochiral propranolol. Additionally, the enzymatic resolution of the following intermediates was reported: 1-azido-3aryloxy-2-propanols, 4-(1-aryloxy)-3-hydroxybutyric acid esters, glycerol and cyanohydrin derivatives. However, even the highly enantioselective lipase-catalyzed process can only provide 50\% of the starting racemate in an optically active form. An alternative method such as a reduction of a prochiral ketone by various strains of yeast might quantitatively provide an enantiomeric product with a yield greater than $50 \%$. The reported substrates for microbial reductions were: 1-halo-aryloxypropan-2-ones and 1-acetoxyaryloxypropan-2-ones.

Keywords: Enantiopure beta-blockers, enantioselectivity, lipases, hydrolases, kinetic resolution of beta-blockers, chiral building blocks, stereoselective reductions, biotransformations.

\section{INTRODUCTION}

$\beta$-Adrenergic blocking agents (so called $\beta$-blockers) are drugs that show marked efficacy in angina pectoris, hypertension, cardiac arrhythmias, migraine headaches and other disorders related to sympathetic nervous system [1]. As cardiovascular diseases are the world's leading cause of death, accounting for $20-50 \%$ of total death rates, unsurprisingly among the top 200 world prescriptions of 2004 several $\beta$-blockers, such as atenolol, metoprolol, bisoprolol and propranolol Fig. (1) are presented [2].

It is now well established that the biological activities of molecules have close relationships with their chemical structures and that the chirality of the molecule plays an important role in its biological activity. Consequently, in the most bioactive substances such as drugs consisting of one or more optical centers, only one of the enantiomers may contribute to the biological activity. In $\beta$-blockers related to aryloxypropylamines (1) (e.g. propranolol) with the single chiral centre, the $S$-(-) -enantiomer possesses a

*Address correspondence to this author at the Department of Technology and Biotechnology of Drugs, Medical College, Jagiellonian University; Medyczna 9; 30-688 Kraków; Poland; Phone/Fax: +48 1265704 88;

E-mail: mfkonono@cyf-kr.edu.pl much greater affinity for binding to the $\beta$-adrenergic receptor. The eudysmic ratios of the various $\beta$-adrenergic blocking agents vary considerably, but in all cases (with the exception of sotalol, ethanolamine derivative, for which the $(R)$-sotalol possess the $\beta$-blocking activity), the ( $S$-enantiomer is the active one. Except for a few medicaments e.g. timolol, levobunolol all of these drugs are marketed as the racemates. This has probably been influenced by the fact that they are difficult to separate by classical methods and that the distomer was believed to exhibit no serious side-effects. However, over a period of time the situation has been changing rapidly, the SWORD study [3] showed, that the distomer of sotalol increased mortality in patients with myocardial infarction compared with placebo. Even if distomers of the other $\beta$-blockers generally exhibit no other serious side-effects, they are still considered as an unnecessary isomeric ballast as they produce the same sideeffects as eutomers, without contributing to the desired therapeutic effects [4]. The degree and the direction of pharmacokinetics in this class of drugs are also influenced by chirality [5].

The number of papers in the literature describing reactions catalyzed by enzymes and microorganisms as a method for obtaining enantiomerically pure compounds is increasing considerably. The usefulness of biocatalysts in 


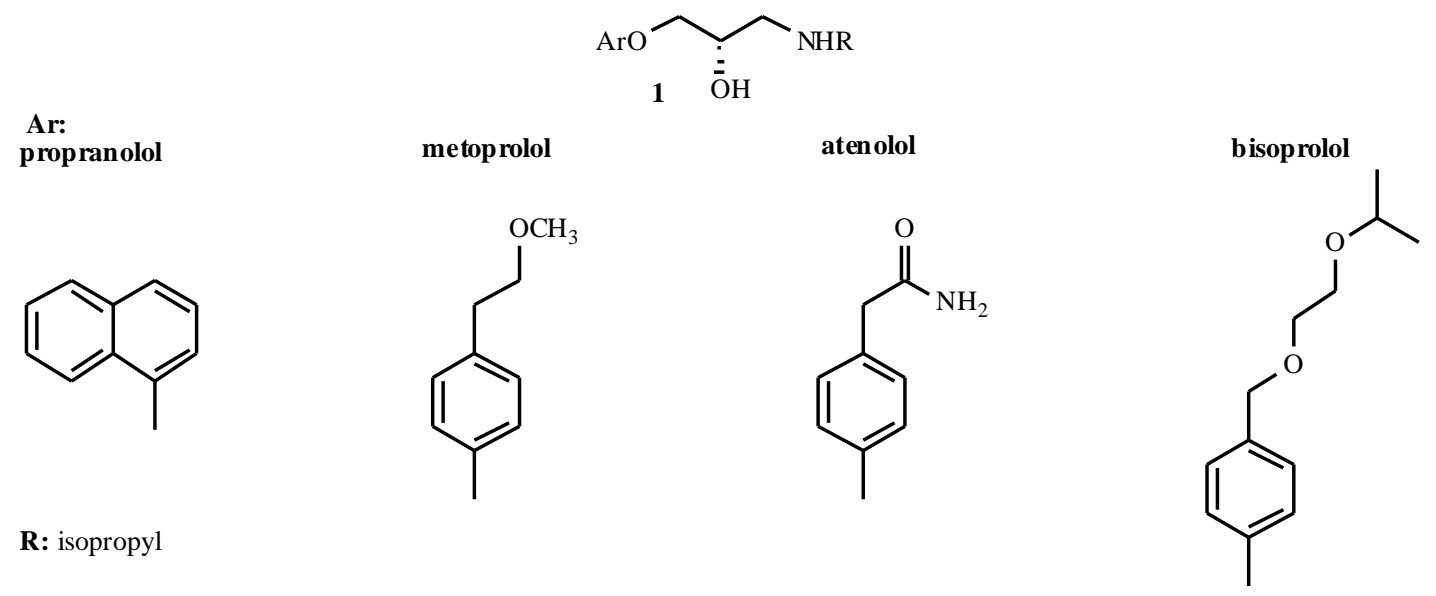

Fig. (1). Typical structures of (S)- $\beta$-blockers with the aryl substituents: propranolol, metoprolol, atenolol, bisoprolol.

organic chemistry and for pharmaceutical applications is now well documented [6-10].

Until now, however, there has been only one paper focusing on use of lipase in the preparation of $\beta$-blockers [11]. Margolin has mentioned [12] a few methods useful in biosynthesis of propranolol by using hydrolases. This review describes relevant papers considering approaches for optically active $\beta$-blockers or their building blocks. We aim to quantify the characteristics of processes that have been described so far with respect to the type of product, catalyst, conversion and optical purity. Most of the reported biotransformations reveal that hydrolases and redox biocatalysts are the prominent categories.

\section{KINETIC RESOLUTION WITH HYDROLASES}

Reactions catalyzed by various types of hydrolases are predominant among biotransformations. Lack of sensitive cofactors, which have to be recycled, makes them particularly attractive for organic synthesis. Among hydrolytic enzymes lipases and esterases are frequently used because they accept a broad range of substrates and often exhibit high enantioselectivity [13,14]. Researchers now can choose from a large number $(>50)$ of commercial lipases and esterases. Lipase-catalyzed reactions in organic solvents are becoming increasingly important in enantioselective synthetic chemistry, as certain reactions which are sensitive to water can be effectively carried out in organic media.

There are several advantages of carrying the process in organic media, such as better solubility of substrates, easier recovery of product, enzyme and finally the enantioselectivity in organic solvents is often higher than that of corresponding hydrolytic reaction in water. However, there are also some drawbacks of this process - especially a slow reaction rate, and a decrease of optical purity of the desired product due to the reversible nature of the process. In addition, the maximum yield of kinetic resolution is only $50 \%$, which is economically and ecologically unattractive.

\section{Single Step Approaches for Optically Active $\beta$ - Blockers}

The first reported approaches to direct resolution of propranolol were unsuccessful [15]. As in the preliminary experiments $N, O$-diacetyl-propranolol failed to be a substrate for proteases, lipases and esterases tested by Shieh, the computer aided molecular modelling was used to help in the prediction of substrates for biocatalytic reactions [16]. Presumably, the methyl group of the $O$-acetate sterically prevented the access to the carbonyl group of the nucleophilic residue in the enzyme pocket, thus the enzymatic hydrolysis was unabled. When the acyl moiety was changed by removing the methyl from the carbonyl group - resulting in ( \pm )-N,O-bis(methoxycarbonyl) derivative of propranolol (2) and exposed to various esterases (pig liver, cholesterol and porcine pancreatic) - the racemic compound was readily hydrolyzed to yield (R)-Nmethoxycarbonylpropranolol Fig. (2A). The best percent of conversion $(40 \%)$ and enantiomeric excess $(\mathrm{ee}=83 \%)$ of hydrolyzed product as well as $\mathrm{E}$ standard value around twenty calculated according to Chen [17] was obtained with the use of porcine pancreatic esterase. $E$ value is the ratio of the activity towards each isomer $E=\ln \left[\left(1-e_{s}\right)\left(e_{p} /\left(e_{s}+\right.\right.\right.$ $\left.\left.\left.e e_{p}\right)\right)\right] / \ln \left[\left(1+e_{s}\right)\left(e_{p} /\left(e_{s}+e_{p}\right)\right)\right], e_{s}$ and $e_{p}$ are enantiomeric excess of the recovered substrate fraction, and the enantiomeric excess of the product fraction respectively.

The stereoselective opening of epoxide ring of 4 by 2propylamine (5) Fig. (2B) in the presence of a porcine pancreatic lipase (PPL) was studied by Kamal [18]. In opposition to previous work, this method offered the advantage of carrying the reaction in organic media and thus enhancing its suitability for the water-susceptible or insoluble substrates. Moreover, the effect of solvents on the aminolysis was studied, pointing out that the best reaction medium was toluene. In case of non-substituted phenoxy derivative and para-substituted phenoxy derivatives ee ratio exceeded $99 \%$ and gave the high rate of conversion (over $40 \%)$.

Finally, the kinetic resolution of propranolol Fig. (2C) has been achieved by a lipase catalysed $N$-acetylation of the secondary amino group [19]. Among several enzymes used, Candida cylindracea lipase (CCL) was found to be the most reactive and enantioselective for catalysing the $\mathrm{N}$-acetylation of propranolol with isopropenyl acetate. The stereoselectivity of an enzyme is strongly affected by hydrophobicity, functionality and structure of the reaction medium, therefore the influence of the solvent has been studied, and isopropyl ether was shown to be the most suitable. The outcome of 
this process showed moderate ee values of the obtained inactive $(R)$-propranolol $(67 \%)$ and slightly better for $(S)$ amide 7 - $73.4 \%$.

\section{Chiral Building Blocks}

Chiral reagents and building blocks play important roles in the manufacturing of modern pharmaceutical drugs. Hence, efficient and selective ways are needed to produce useful chiral building blocks. Chiral alcohols represent a highly versatile and attractive group of intermediates for $\beta$ blockers synthesis.

\section{A. Chlorohydrins}

One of the drawbacks of lipase catalyzed resolutions is reversibilty of the process of transesterification. To overcome this problem an irreversible procedure was developed for the resolution of alcohol compounds using enol esters as acylating agents [20]. The transesterification process in organic solvents has another defect - a very slow reaction rate, which limits the application of this process. The immobilization of lipoprotein lipase from Pseudomonas species (LPL, Amano) on nonionic resine XAD-8 was proved to accelerate the reaction rate of the process 20 to 200 times. It was probably due to the homogeneous distribution of enzyme on the surface of the immobilizing agent or to the fact that XAD-8 may absorb the substrate to increase the contact with the enzyme. The immobilized enzyme showed also high enantioselectivity. The obtained chiral (R)-1chloro-3-(1-naphthyloxy)-2-propanol was useful in synthesis of (S)-propranolol hydrochloride (achieved by its treatment with sodium hydroxide in ethanol followed by a reaction of the resulting epoxide with excess of isopropylamine).

Bevinakatti [21] described acylation and deacylation/ hydrolysis processes of the same compound $(\mathrm{R}=$ fused benzene ring) Fig. (3). A purified enzyme lipase from
A<smiles>COC(=O)OC(COc1cccc2ccccc12)CN(C(=O)OC)C(C)C</smiles>

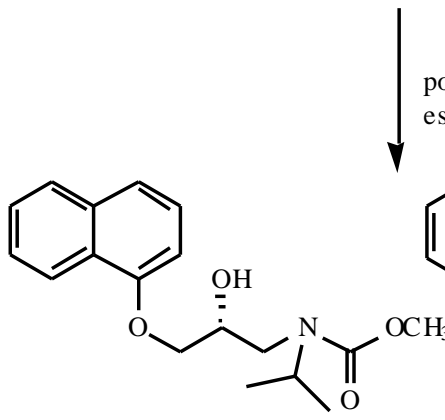

$(R)-3$
B<smiles>[R]c1ccc(OCC2CO2)cc1</smiles><smiles>CC(C)NC[C@H](O)COc1c[R]ccc1</smiles>

C<smiles>CC(C)NCC(O)COc1cccc2ccccc12</smiles>

propranolol<smiles>CC(=O)ON(C[C@H](O)COc1cccc2ccccc12)C(C)C</smiles>

CCL

Isopropenyl acetate<smiles>CC(C)NC[C@H](O)COc1cccc2ccccc12</smiles>

Fig. (2). Biosynthesis of propranolol enantiomers. 
Pseudomonas cepacia (Lipase PS Amano LPSA) was found to show an excellent selectivity toward the isomer $(S)-8$. At the conversion rate around $50 \%$, the transesterification reaction of acetate 9 using n-butanol in diisopropyl ether (DIPE) produced $(S)$-chlorohydrin 8 and $(R)$-acetate 9 in $>$ $95 \%$ ee $(\mathrm{E}=>100)$ Fig. (3B). While hydrolysis worked faster than transesterification, the ease of workup and isolated yields were in favor of the latter. In the acylation studies of $\mathbf{8}$ Fig. (3A), LPSA showed also excellent selectivity toward the $(S)$-isomer using vinyl acetate (VA) or acetic anhydride as an acylating agent. Another notable factor for all the LPSA-catalyzed reactions was that the initial rate of reaction drastically dropped down after $40 \%$ conversion, coming practically to halt around $50 \%$ after consuming the entire $(S)$-isomer.

A

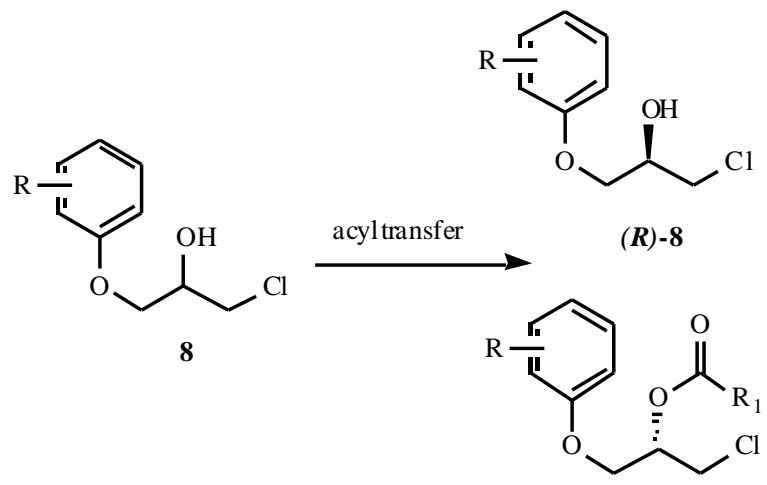

(S)-9

B

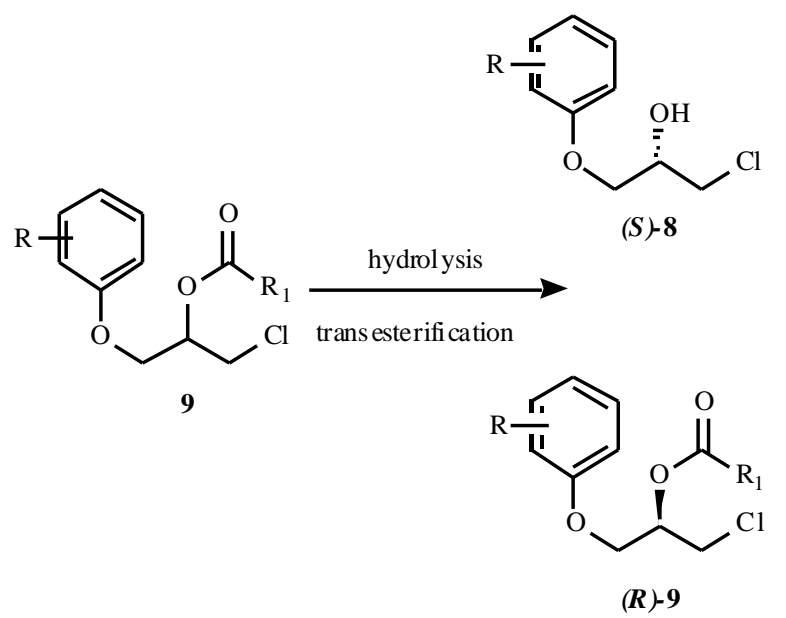

Fig. (3). Types of reactions catalyzed by hydrolases in kinetic resolutions of chlorohydrins.

The above described protocol was extended to the synthesis of both enantiomers of atenolol [22] and practolol [23]. In the same year Schneider published three reports concerning the problem of choosing the most suitable biocatalyst [24], synthetic intermediates for $\beta$-blockers [25] and the influence of the substitution pattern on both activity and enantioselectivity of the selected enzyme [26]. As the result biologically active $(S)$-isomers of propranolol, toliprolol, moprolol, alprenolol, penbutenol, atenolol, practolol and oxprenolol were obtained. The first part of the experiments covered enzymatic hydrolysis of 2-butyloxy-1chloro-3-phenoxypropan (9) by a number of isolated esterhydrolases. From the obtained data it was obvious that the best suitable biocatalysts were the lipases from Mucor miehei and Pseudomonas sp. As the latter was showing much higher specific activity it was chosen for further experiments. The question aroused which was the most suitable substrate and type of reaction for this enzyme. It was proved that for the most appropriate substrate - aryloxy 1-chloro-2-propanol (8) - a more enantioselective and more efficient method was the acetylation $(\mathrm{E}=223)$ compared to the hydrolysis $(E=107)$. Another problem was the influence of the hindered aryl substituted halohydrins on the enantioselectivity of enzymes. The ortho-substituted derivatives displayed lower specific activities as compared to meta- and para-substituted ones. This effect was clearly reflected in the considerably longer reaction times required for the conversion of $o$-substituted compounds.

Sinisterra [27], in opposition to the previously mentioned paper, concluded that the relationship between the enantiomeric excess and the type of enzyme used was unclear. At the same time, a wide variety of results depending on the enzyme used have been reported, which cannot be "extrapolated" for other substrates. If we take into consideration the wide variety of structures that include $\beta$ blockers of type 1, whose cardioselectivity is partially conditioned by the substituted aromatic system, this problem is even more complicated [28]. Sinisterra [27] showed that lipase B of Candida antarctica (CALB) works quite unspecifically with groups of very different physicochemical characteristics which suggests a wide structural tolerance near the active site of this lipase. It was demonstrated that this enzyme was particularly suitable for the resolution of aryloxypropanolamines of structure $\mathbf{1}$, being much better than other used biocatalysts to the synthesis of practolol, metoprolol, which are substituted in phenyl ring only in para-position.

The enzymatic hydrolysis of 9 with the use of Candida cylindracea lipase (CCL) [29] was described to lead to the appropriate enantiomer. Quite good results with the acetylation process of $\mathbf{8}$ in the organic solvent $-n$-heptane using isopropenyl acetate and lipase powder PS (Amano) were reported by Raju [30].

Lipase from Pseudomonas cepacia showed poor activity and moderate enantioselectivity (E) in pure aqueous systems in hydrolysis of a racemic mixture of $\mathbf{9}$. Since this substrate is generally insoluble in water and partially soluble in hydrophobic solvents such as hexane and octane, a mixture of hydrophilic organic solvents and aqueous buffer was used to study the initial reaction rate [31]. Complete solubilization of the substrate in water by addition of polar organic solvents was reported to reduce the catalytic property of lipase which led to the conclusion that the oil/water interfacial surface plays an important role in the resultant kinetic properties of the enzyme. Another report by these authors concerned suitable medium engineering and enzyme immobilization and PEG modification to obtain the desired high optical purity of products [32]. They used a few different polar organic solvents (acetone, DMSO, 1,4dioxane, DMF, 1-propanol, tetrahydrofuran). In general the activity increased with the increase of the polarity of the 

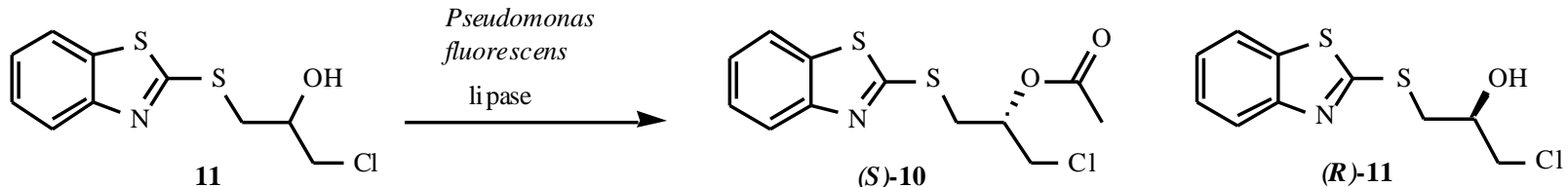

Fig. (4). Kinetic resolution of arylothiohalohydrin - precursor molecule of potential $\beta$-blocker.

solvent, whereas the enantioselectivity behaved in the opposite way. They concluded that in the $\log \mathrm{P}$ range for solvents between -1 and 0 (the logarithm of the partition coefficient of a given solvent between 1-octanol and water), the enantioselectivity and activity of the enzyme remained constant. In most large-scale reactions both enantioselectivity and the reaction rate are important. In such cases, an inexpensive and non-toxic polar solvent such as acetone can be chosen as cosolvent in which both - enantioselectivity and reaction time - are moderate. The study on the effect of immobilization by entrapment in alginate gel with respect to activity, enantioselectivity and stability of the enzyme showed that an average $E=50$ was determined for the entrapped enzyme. It was 4-5 times greater than in case of the native enzyme. The enzyme was modified by using PEG-DNCP (PEG-dinitrophenylcarbonate) as a modifier before the entrapment in the alginate beads. The use of PEG has two advantages: it makes the enzyme more stable against proteases, thermal influence and it reduces its leaching from the beads over a long time. Further increase of the activity could be observed by modifying the lipase with PEG. However, this modification did not result in a higher enantioselectivity. Entrapment of the enzyme in Ca-alginate gel beads resulted in a significant increase in the enantioselectivity of the native and PEG-modified lipase. This result can provide some direction for the optimization of lipase activity and enantioselectivity for $\beta$-blocker synthesis with immobilized lipases.

Kapoor reported a kinetic resolution of $\mathbf{8}$ by stereoselective hydrolysis of its acyl derivatives. In the experiment whole cell preparations containing enzymes from native sources were used and results compared with those obtained using crude commercial lipases [33]. Lipase PS "Amano" (PSL), Candida antarctica lipase (CAL A+B)immobilized on Sol-Gel AK and Mucor javanicus lipase (MJL) were compared with two native strains from the Institute's repository: Trichosporon sp. RRLY-15 and Bacillus sp. RRL-1789. Additionally Pig Liver Acetone Powder (PLAP) was prepared from the fresh pig liver and was used in the form of whole cells. The greatest selectivity toward (S)-ester 9 showed MJL (E>300, ee $>99 \%$ ) for butanoyloxy derivative, while PSL showed faster hydrolase's activity with moderate enantioselectivity $(\mathrm{E}=18$, $\mathrm{ee}_{\mathrm{p}}=85 \%$ while Bevinakatti [21] reported ee $>95 \%$ ). CAL, on the other hand, was proved to be the most sluggish enzyme and showed moderate enantioslectivity $\left(E=22\right.$, $\left.e_{\mathrm{p}}=87 \%\right)$. As expected, all three commercial lipases exhibited a preference for the $(S)$-enantiomer, thus following the Kazlauskas's rule of selectivity [34]. However, Trichosporon sp. RRLY-15 [33] was found to be the best one, displaying the highest selectivity (E>550). In fact among all the enzymes and microorganisms studied for the stereoselective hydrolysis, RRLY-15 established its superiority with respect to high enantioselectivity and moderate rate of hydrolysis.
Furthermore RRLY-15 produced the desired alcohol $(R)-8$ with the highest enantioselectivity from its acetyl derivative. Both RRLY-15 and PLAP behaved like esterases, showing reverse selectivity (preference for the $(R)$-enantiomer) compared to results obtained from commercial lipases. Another important characteristic of RRLY-15 was the reversal of the selectivity with an increase in the size of the alkyl group from acetyl to butyryl, which was not observed in case of any other strain mentioned in this report.

Scilimati [35] described a kinetic resolution of 1(benzothiazol-2-yl-sulphanyl)-3-chloropropan-2-ol(11) Fig. (4), a precursor of molecules with a potential $\beta$-blocker activity. The $O$-acetylation was performed by $\mathrm{VA}$ in the presence of the following lipases from Pseudomonas sp., Pseudomonas fluorescens, Candida cylindracea and Lipase G. The reported data showed, that $(S)$-acetyl $\mathbf{1 0}$ and respective $(S)$-alcohol $\mathbf{1 1}$ could be prepared with enantiomeric excesses up to $93 \%(\mathrm{E}=43)$ in case of Pseudomonas fluorescens lipase. Presumably, even higher values could be expected by stopping the reaction at lower conversion rate (in this case $31 \%$ ). High ee values might be also obtained if pure, rather than crude lipase powder is used, as the latter could contain in fact, more than one hydrolytic enzyme, probably with opposite selectivity.

\section{B. Diols}

Chiral glycerol derivatives are versatile building blocks for the syntheses of several types of chiral medicines including $\beta$-blockers and also platelet activating factor (PAF) and PAF antagonists. Hydrolysis of 1,2-diacetoxy-3chloropropane (12) Fig. (5) by more than 10 commercially available lipases was reported by Iriuchijima [36]. The lipoprotein lipase from Pseudomonas aeruginosa showed a very good specificity toward $(R)$-isomer $\mathbf{1 3}$, leaving the $(S)$ 12 with the optical purity $90 \%$. The optically active $(S)$ isomer was converted in four steps to $(S)$-propranolol with the same optical purity. The authors obtained also $(R)$ propranolol with $77 \%$ of optical purity. It was indicated that this substrate can be also used in the synthesis of $(S)$ oxprenolol.

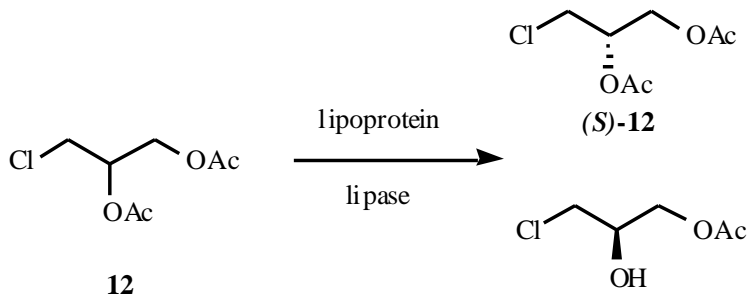

(R)-13

Fig. (5). Kinetic resolution of 1,2-diacetoxy-3-chloropropane.

An enzymatic resolution of 2-substituted glycerol derivatives was exploited by Achiva [37] in the synthesis of (S)-propranolol. He employed the lipase $\mathrm{P}$ from 
Pseudomonas fluorescens and examined the esterification of 2-O-benzylglycerol (14) Fig. (6A) with various acetates in organic media. VA promoted this reaction with a high enantioselectivity (up to $94 \%$ ee ) to afford (S)-2-Obenzylglycerol-1-acetate (15), which was incorporated in the synthetic sequences leading to the $(S)$-propranolol. A variety of 3-(aryloxy)-1,2-propanediol derivatives 16 with different substituents on the aromatic ring or at the primary hydroxy group were used as the substrates for the lipase from Pseudomonas cepacia (Amano PS - formerly called lipase P from Pseudomonas fluorescens) in a kinetic resolution by transesterification with VA in the studies performed by Theil [38]. The diols were acylated in two sequential steps Fig. (6B). In the first step the racemic 1,2-diols were acylated regioselectively at the primary hydroxy group without enantioselection. The subsequent acylation at the secondary hydroxy group of the formed racemic primary monoacetate was responsible for the high enantioselection. It was confirmed that the enantioselectivity of this transformation significantly depends on the substitution pattern of the aryl ring and the organic solvent used. 3-(aryloxy)-1,2propanediols 16 with substituents in the para-position showed a much higher enantioselectivity than the corresponding derivatives with ortho-substituents. The best substrates in the crucial second reaction step, regarding aryl substituents, were the derivatives with branched alkyl substituents in $p$-position. On the other hand, compounds with more bulky $o$-subsubstituents, such as tert-butyl, phenyl and benzoyl, furnished very weak substrates for lipase PS. It was shown, that there is a significant influence of the length of the introduced acyl residue at primary hydroxy group on the $\mathrm{E}$ value of the reaction. The best selectivity has been found for the derivatives with the substituents bearing 2, 6, 10 and 16 carbon atoms respectively.

Continuing, Sinisterra carried out the hydrolysis of the diacetate of 3- $\alpha$-naphthyloxypropane-1,2-diol (18) Fig. (6C) and the acylation of the respective diol in order to study the regioselectivity and stereoselectivity of immobilized lipase B from Candida antarctica (CALB) on polymeric resin (Novozym 435, Novo Nordisc) [39]. In the first attempts 3$\alpha$-naphthyloxypropane-1,2-diol was acylated with VA in different solvents. The regioselectivity towards the primary alcohol was very high, but low or moderate enantioselectivity was observed in the acylation leading to diacetate 18. A similar behavior has been described for the lipase of $P$. cepacia and an analogous compound in previously described studies. The hydrophobic solvents such as diethyl ether gave better yields compared to more hydrophilic solvents, but the obtained ee and E values were moderate to poor. Generally, very high regioselectivity towards the primary hydroxyl group but usually low enantioselectivity has been observed for the lipase-catalyzed acylations of 1,2-diols, whereas hydrolysis of 1,2-diol

A

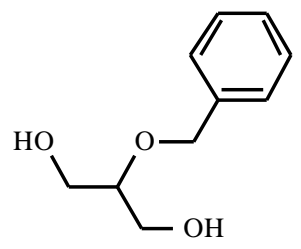

14

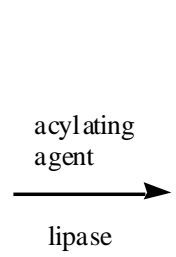

pase

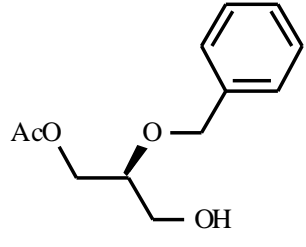

(S)-15

B

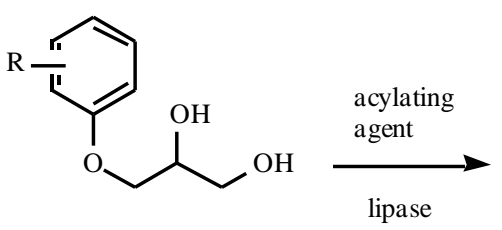

16

C
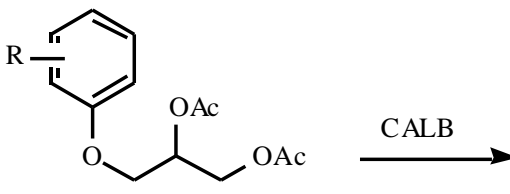

18

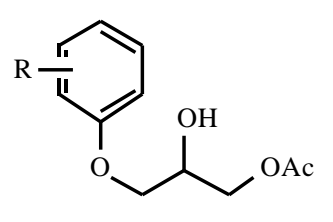

17

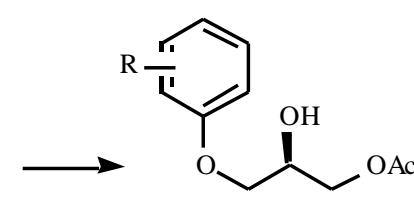

(R)-17

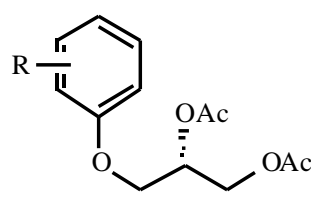

(S)-18

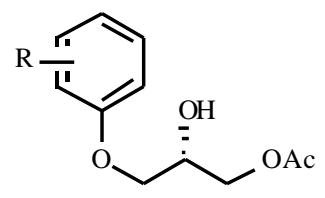

(S)-17

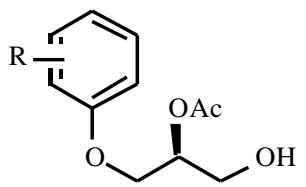

(S)-19

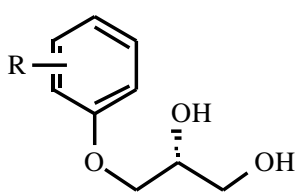

(R)-16

Fig. (6). Kinetic resolution of aryloxydiols. 
diacetates with the same enzyme proceeded with moderate regioselectivity but higher enantioselectivity (giving a mixture of monoacetate $(S)-\mathbf{1 7}$ and diol $(R)-\mathbf{1 6}$ as major products).

De Amici [40] obtained stereoisomers of a $\beta$-adrenergic receptor antagonist $\left(\Delta^{2}\right.$-isoxazoline derivative) structurally related to falintolol by an enzyme-catalyzed kinetic resolution of the unsaturated secondary alcohol $\mathbf{2 0}$ (used as an intermediate). This reaction was followed by its cycloaddition to pyruvonitrile oxide. The derivatives related to 3-butene-1,2-diol (20) Fig. (7) were acetylated on their secondary alcohol group. The best results gave lipase PS and CALB resulting in compounds $(S)-20$ and $(R)-21$. Through this strategy aminoalcohols of $\Delta^{2}$-isoxazoline were obtained with $99 \%$ and $92 \%$ enantiomeric excess respectively.<smiles>C/C(=N\OCC(O)CNC(C)(C)C)C1CC1</smiles>

falintolol<smiles>[R]OC[C@@H](O)C=C</smiles>

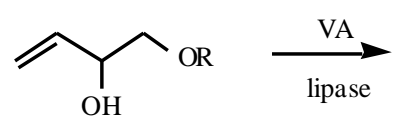

20 a - c
(S)-20 a - c<smiles>[R]OC[C@H](C=C)C(C)=O</smiles>

(R)-21 a - c a: $\mathrm{R}=\mathrm{COC}_{3} \mathrm{H}_{9} ;$ b: $\mathrm{R}=\mathrm{CO}$
c: $\mathrm{R}=\mathrm{Si}(\mathrm{Ph})_{2} \mathrm{C}\left(\mathrm{CH}_{3}\right)_{3}$

Fig. (7). Kinetic resolution of precursors of structures related to falintolol.

The transacetylation of 2-hydroxybut-3-enylbutyrate (20a) under the catalysis with different lipases gave the moderate enantioselection, as reflected by the low values of the enantiomeric ratio (E). Accordingly, a residual monoester was obtained as a single enantiomer only by increasing the degree of conversion. An inversion of the enantiopreference was detected on passing from CALB to Pseudomonas fluorescens lipase. Since the goal was to synthesize enantiomers with very high enantiomeric excess, the biotransformation of other derivatives, which were characterized by the presence of a sterically hindered ester 20b or silyl ether 20c respectively, were investigated. The results of transesterification of these substrates revealed that these structural modifications taken into account significantly improved the enantioselectivity. Among tested

enzymes, lipase PS was the most selective catalyst of the transacetylation of derivative 20b (E>100).

\section{Hydroxyesters}

Other chiral precursors in the synthesis of $\beta$-adrenergic blocking agents are 3-hydroxyesters 22. In case of these substrates there are three major possibilities for lipase catalyzed-reactions: hydrolysis, esterification and transesterification. Scheper [41] applied the last mentioned process to the resolution of an aliphatic 3-hydroxyester with the use of different lipases and VA as an acyl donor. The reactions were performed in organic solvents and the influence of the amount of water added was investigated. The results indicated that for transesterification reactions in hydrophobic organic solvents the addition of water is not necessary. In the optimized system for lipases from Pseudomonas cepacia (PCL) the resolution of $\mathbf{2 2}$ was tested. The enantioselectivity towards the aromatic compounds was proved to be much higher compared to the aliphatic ones. Enantiomerically pure precursors of propranolol and alprenolol were prepared by Bornscheuer [42]. The lipasecatalyzed kinetic resolution of racemic 3-hydroxyesters 22 either by $O$-acylation or hydrolysis of the ester group were compared Fig. (8). Both approaches were highly enantioselective $(>95 \%$ ee) with $\mathrm{E}$ values $>150$ in case of the use of PCL. Lipases from Chromobacterium viscosum (CVL) and Candida rugosa (CRL, formerly classified as Candida cylindracea Amano AY30) also proved their suitability in these reactiones. Compound $\mathbf{2 2}$ was subjected to either lipase-catalyzed hydrolysis in aqueous phosphate buffer/toluene or acylation with VA in hexane using PCL. The reaction of hydrolysis resulted in the formation of a highly pure acid in the desired $(S)$-configuration $\mathbf{2 3}$. On the other hand, it was found out that the acylation with VA was even more enantioselective and faster, yielding the acetate in $(R)$-configuration 24 with the ee $=99 \%$.

\section{Azidoalcohols}

The first attempts on the enzymatic resolution of racemic 1-azido-3-aryloxy-2-propanols $\mathbf{2 5}$ and their corresponding acetates were mentioned by Ader [25]. The resolution of racemic compounds by lipase from Pseudomonas sp., which catalyzed acylation or hydrolysis of the acetate proceeded with enantiomeric ratios $\mathrm{E}=21$ and 55 , respectively.

To establish the general scope and applicability of this biocatalytic method, Pchelka [43] undertook a detailed study of kinetic resolution by transesterification of a larger range of racemic azido alcohols 25 Fig. (9). The influence of several parameters in order to improve the enantioselectivity of this method was investigated. The best results were obtained with immobilized lipase from Candida antarctica fraction B (Novozym $^{\circledR}$ SP 435, Chirazyme ${ }^{\circledR}$ L-2, c.-f., C2, lyo.). In

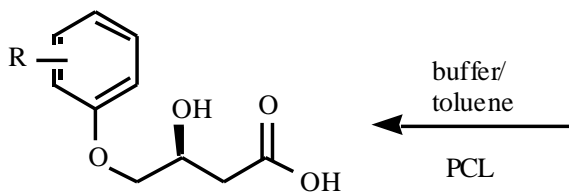

(S) -23<smiles>[R]OC(=O)CC(O)COc1ccccc1</smiles>

22

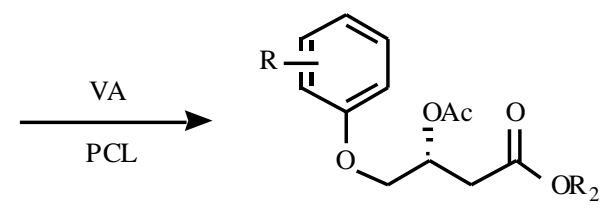

(R)-24

Fig. (8). Kinetic resolution of 3-hydroxyesters. 
Pchelka study it was shown that the activity of Novozym SP 435 in transesterification of $\mathbf{2 5}$ was higher in solvents of low polarity as judged by their $\log$. Changing the enzyme from Novozym to Chirazyme in the transesterification of the same substrate $\mathbf{2 5}$ in toluene as well as in benzene did not alter the reaction rate considerably, but led to a noticeable decrease in the enantioselectivity. This fact was slightly surprising as these two enzyme preparations are identical according to the provider. The influence of various acyl donors was screened for the Novozym SP 435-catalyzed transesterification of $\mathbf{2 5}$. The use of enol esters resulted in higher enantioselectivity ( $\mathrm{E}=23-43)$ when compared to ethyl acetate $(E=15)$. The higher ee values of products were observed in case of isopropenyl acetate. The reaction of racemic 25 was carried out with termostable Novozym SP 435 at the temperatures ranging from 4 to $80^{\circ} \mathrm{C}$. At $4^{\circ} \mathrm{C}$ the $\mathrm{E}$ value was markedly increased and reached 72 for $51 \%$ of conversion. When the temperature was increased up to $40^{\circ} \mathrm{C}$ the reaction time decreased from 50 to 3 hours but the enantiomeric ratio decreased to 33 . Further elevation of the temperature induced considerable decreases in the enantiomeric ratio.

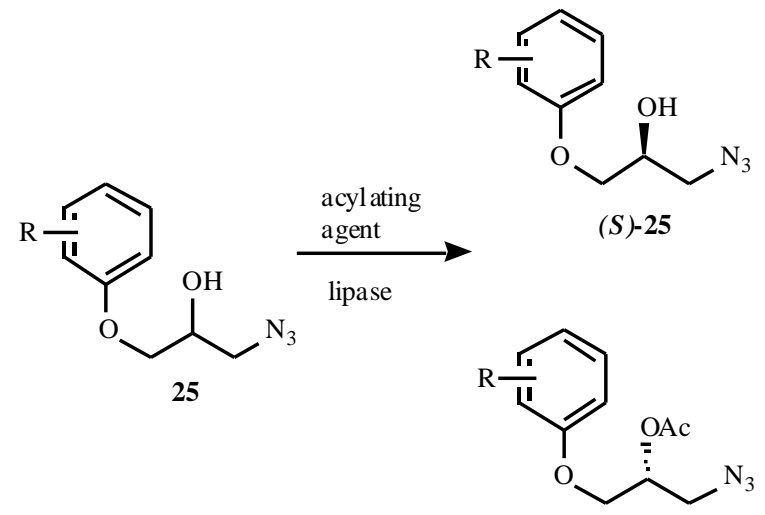

(R) -26

Fig. (9). Resolution of azidoalcohols by esterification.

Among all tested additives only TTCHD-D (1,5,9,13tetrathiacyclohexadecane-3,11-diol) was found to have beneficial effects on the reaction time and enzyme enantioselectivity (E from 40 to 50 ).
Successful enzymatic resolution of $\beta$-azido alcohols in combination with ruthenium-catalyzed alcohol isomerisation was described by Bäckvall [44]. To overcome the major drawback of kinetic resolution (maximum yield - 50\%) dynamic kinetic resolution (DKR) was proposed. This procedure was applied to the enantioselective synthesis of different phenyl and aryloxymethyl substituted azido alcohol derivatives. The preliminary results of kinetic resolution of 25 with the use of 3 commercially available enzymes showed that the best enantioselectivity was obtained using CALB (Novozyme 435, N-435). On this basis, the kinetic resolution of $\mathbf{2 5}$ using $\mathrm{N}-435$ and $p$-chlorophenyl acetate as an acyl donor was combined with a ruthenium-catalyzed racemization process via hydrogen transfer with a catalyst. (S)-3-azido-1-(naphthalen-1-yloxy)propan-2-yl acetate $(S)$-(26) - the precursor for $(S)$-propranolol was achieved with $86 \%$ ee but with an excellent yield, $75 \%$.

\section{E. Nitriles}

A concept of cyanohydrins as versatile compounds in the synthesis of propranolol was presented by Matsuo [45]. The ability of Pseudomonas sp. lipase to hydrolyze 1-cyano-2(naphtalen-1-yloxy)ethyl acetate (27) Fig. (10A) was shown, though it was the unreacted ester that was used in the further synthesis of $\beta$-blocker. Wong [46] described the procedure of transesterification of respective compound in organic media. He emphasized the fact that this might be a way of avoiding racemisation of cyanohydrin. The investigation of enzymatic resolution of other nitriles such as 4-aryloxy-3hydroxybutanenitriles 29 Fig. (10B) and their application towards the synthesis of $(S)$-propranolol, $(S)$-alprenolol and (S)-moprolol was presented by Kamal [47]. Pseudomonas cepacia lipase was the most suitable lipase for reactions carried out in DIPE. Immobilization provided a revolutionary change in the enantioselectivity and the reaction rate of this transesterification. PS-D (Pseudomonas cepacia lipase immobilized on diatomite) catalyzed this reaction affording enantiomerically pure $(S)$-alcohol with ee value 92.6 and the acetate $\mathbf{3 0}$ with ee> $98 \%$ resulting in an $\mathrm{E}$ ratio of 311. Lipase from Pseudomonas cepacia immobilized on modified ceramic particles (PS-C) provided excellent yield with high enantiomeric excess in a short period of time. Furthermore, the transesterification process by this immobilized lipase was comparatively much faster

A<smiles>CC(=O)OC(C#N)COc1cccc2ccccc12</smiles>

B

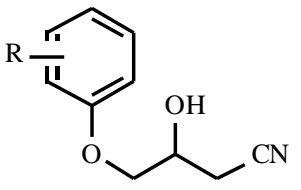

29

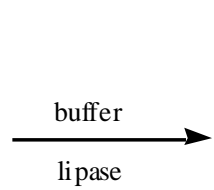<smiles>N#CO[C@@H](C#N)COc1cccc2ccccc12</smiles>

(S)-27<smiles>N#C[C@H](O)COc1cccc2ccccc12</smiles>

(R)-28

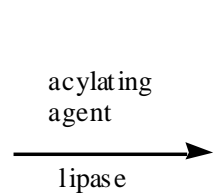

lipase

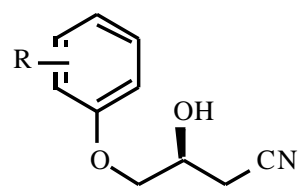

(S)-29

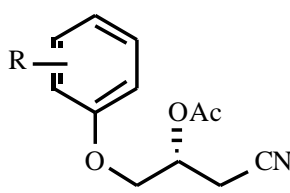

(R)-30

Fig. (10). Kinetic resolution of nitriles. 
that the use of an unimmobilized lipase PS. It was also observed that DIPE, hexane, diethyl ether and toluene are the solvents of choice offering remarkable enantioselectivity, whereas in hydrophilic solvents such as acetone, tetrahydrofuran and acetonitrile the reaction proceeds with lower conversion rate.

\section{STEREOSELECTIVE REDUCTION}

The reduction of prochiral ketones can be performed with the use of whole cells (e. g. baker's yeast) or purified enzymes. The whole cells procedure offers the advantage of the cofactor being recycled in vivo and thus the additive costs of the enzyme purification are avoided. The major drawback of the process in question is the incomplete stereoselectivity of baker's yeast reduction, which might be due to the participation of more than one reductase enzyme with different kinetic parameters and opposite selectivity, or the process might be catalyzed by a single enzyme but with incomplete selectivity. In the majority of cases, the poor selectivity is caused by a competition of two or more enzymes. Because the kinetic behaviour of these competing enzymes is different, the control of the selectivity can be achieved by the reaction conditions. In the case of Saccharomycescerevisiae four of these enzymes have been identified and purified [48]. These enzymes have opposite enantioselectivities and, what is important is that they can be inhibited by different substances and show different substrate profiles. Their different behaviour can be explained because these enzymes are involved in different metabolic pathways. There are two D-enzymes and two L-enzymes with L-enzyme-1 and D-enzyme-2 being the most active. Therefore low ee values are obtained in some cases when using non-natural substrates. There are several factors that can influence the selectivities such as $\mathrm{pH}$, the application of lyophilized cells, various additives such as metal salts, allyl alcohol or $\alpha, \beta$-unsaturated carbonyl compounds, ethyl chloroacetate and similar compounds.

\section{A. Hydroxyketones}

3-aryloxypropane-1,2-diols 16 in enantiomerically pure forms were mentioned as versatile intermediates in syntheses of $\beta$-blockers [38,39]. Lipase-catalyzed acylation of $\mathbf{1 6}$ has been described as a useful method for enantiomeric separation of corresponding diols having meta- and parasubstituted aryl moieties. Alternatively, the reduction of corresponding 3-aryloxy-1-acetoxypropan-2-ones 31 by baker's yeast has been reported by Egri [49] Fig. (11). These transformations with the use of baker's yeasts showed high selectivities for the ketones with $m$ - or $p$-substituted phenyl moieties. Since the opposite tendency (higher selectivity for the less hindered compounds) was found in the lipasecatalyzed processes for similar compounds, the presented baker's yeasts-mediated method seems to be useful for preparing such diols bearing a sterically hindered aryl moiety. Substituted 31, including 1-naphthyloxy-derivative, were reduced with moderate to efficient ee values but with very good yields (up to $82 \%$ ). In the case of the sterically more demanding 1-naphthyl or phenyl derivatives with at least one substituent in the $o$-position, the formation of the corresponding diols 16 with high (>90\% ee) enantiomeric purity was claimed. The reduction of the ketone with a more bulky $m$-substituent moiety proceeded with higher selectivity compared to the compounds with smaller $m$ substituents. The lowest selectivities in these reactions were found for the compounds with $p$-substituted rings. These results might be best interpreted by assuming first a fast enantiotope selective reduction of the acetoxy ketones 31 with a variable degree of $(S)$-enantiomer 17 preference, followed by an enantiomer selective hydrolysis with the preference toward $(R)$-diols $\mathbf{1 6}$.

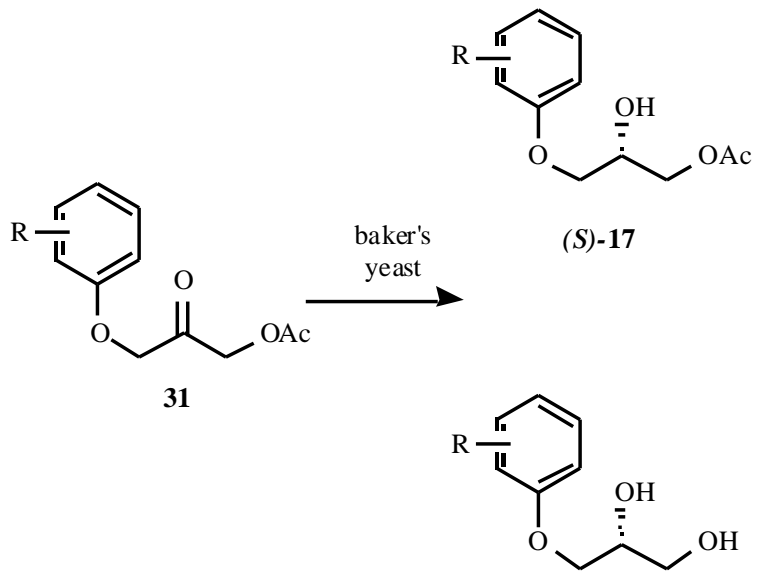

(R)-16

Fig. (11). Stereoselective reductions of hydroxyketones with hydrolysis.

\section{B. Chloroketones}

As it was previously mentioned, the halohydrins $\mathbf{8}$ were proved to be the key intermediates in the preparation of $\beta$ blockers. The reduction of prochiral haloketones 32 by Saccharomyces cerevisiae SIGMA type II was reported by Sinisterra [50] Fig. (12).

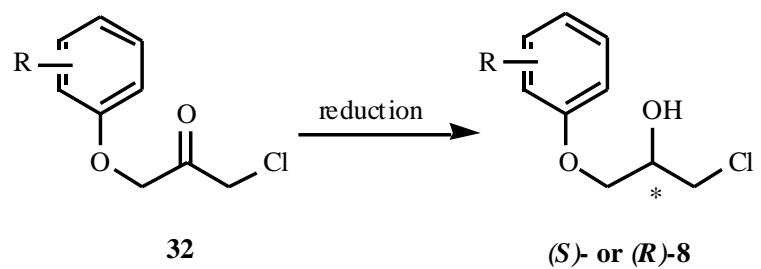

Fig. (12). Reduction of chloroketones.

The investigated 1-naphthyloxy-3-propan-2-one (32) (Rfused benzene ring) was reduced by baker's yeast under various conditions: temperature, amount of cells and time. The stereoselectivity of the process slightly increases with the rising $\mathrm{pH}$ value giving the best result at level 8 (enantiomeric excess of obtained alcohol was 55\%, yield $52 \%)$. It can be explained since at $\mathrm{pH}<7$ baker's yeast cells experience oxidative stress, which causes a decrease in the production of NAD(P)H. Saccharomycescerevisiae SIGMA, type II showed $(S)$-stereopreference. This disagrees with Prelog's rule of stereocontrol, generally described for baker's yeast reductions with the addition of hydride by the $R e$-face. Nevertheless, this statement is not exclusive because the stereocontrol of the process depends on the nature, the size and the electronic characteristic of the substituent at $\mathrm{C}=\mathrm{O}$ 
carbon. It also depends on the presence of several isoenzymes with different stereoselectivity, $\mathrm{pH}$ and temperature profiles. The polar character of chlorine may be the origin of this enantioselectivity [51]. Because $(S)-\mathbf{8}$ is a substrate for $(R)$-propranolol, the enantioselectivity of the process was reversed by a selective poisoning of unnecessary izoenzymes by using ethyl chloroacetate or methyl vinyl ketone. However, the results were not satisfying [50]. Sinisterra suggested that the main alcohol $(S)$-isomer is produced by D-izoenzyme (probably D-enzyme-2) and the $(R)$-isomer is produced by L-enzyme, which is believed to be less active than D-enzymes in commercial strains. The low ee values and unfavorable stereochemistry led to the search for a new substrate for the reduction process. 1-chloro-3(phthalimidyl)-propan-2-on (33) Fig. (13) was proposed to become a new chiral building block that can be used to conventionally prepare the $(S)$-adrenergic $\beta$-blockers of a structure 1 [52]. Still, the results obtained in the reduction of this haloketone $\mathbf{3 3}$ were disappointing. The conversion rates were excellent (yield up to 99\%) at lower reaction times when compared to 32, but the enantiomeric excess was very poor and surprisingly, $(R)$-enantiopreference of 34 was observed. This result suggests that both main enzymes in $S$. cerevisiae exhibit similar activities with this substrate, with the L-enzyme-1 being slightly more active.

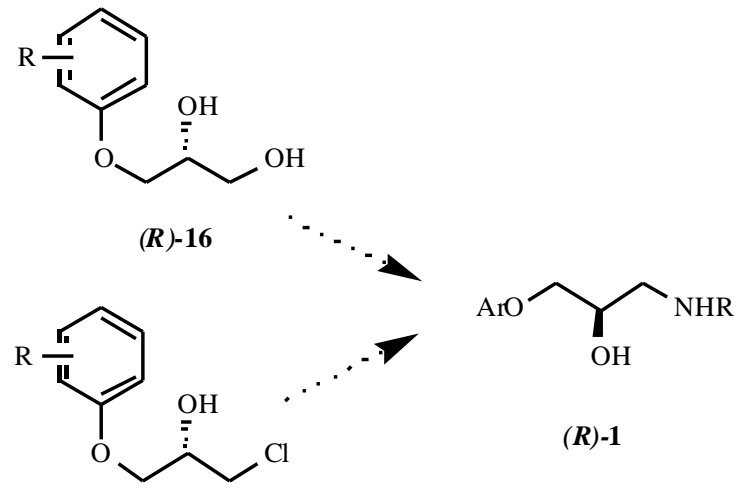

(S)-8
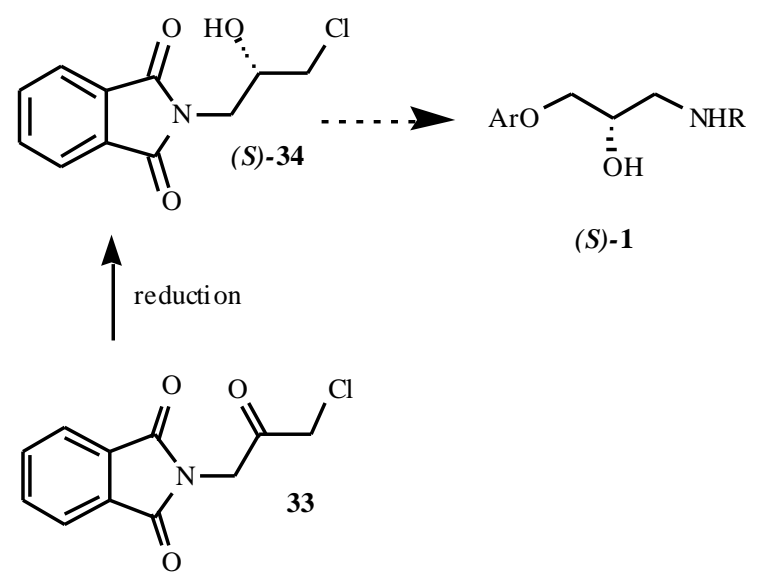

(S)-1

Fig. (13). Precursors for optically active $\beta$-blockers.

Another development in the methodology of controlling the enantioselectivity of biocatalytic reactions is the search for novel biocatalysts. A taxonomic screening of 421 microorganisms was carried out to look for other microorganisms with active alcohol dehydrogenase enzyme
(ADH) [53]. In case of reduction of substrate $\mathbf{3 2}$ the best ee values were reported for Yarrowia lipolytica and Pichia mexicana (achieving $(S)$ - and $(R)$-halohydrin respectively) [54]. From the data presented [52,54] it can be deduced that $Y$. lipolytica, $P$. mexicana and $S$. bayanus are three interesting strains for the process of optimization and scaleup studies. They present a high tolerance to the substrate since the conversion rates and ee values remain high in these cases, especially for the first strain. With the use of Saccharomyces bayanus it is possible to obtain any $(S)$ adrenergic $\beta$-blocker using substrate $\mathbf{3 2}$ as well as $\mathbf{3 3}$, which were reduced to the corresponding $(S)$-halohydrin with the conversion up to $99 \%$ and $67 \%$ ee. In the same studies the optimization of the reaction conditions was carried out. Fresh resting cells were proved to give better ee values and better yields than growing cells because of secondary metabolic reactions of growing cells that transform the substrate.

A new fungus Diplogelasinospora grovesii IMI 171018 which showed high activity and enantioselectivity in the reduction of some polycyclic hydrophobic ketones, was tested in the reduction of haloketones $\mathbf{3 2}$ and 33. In the case of 32 - naphthyloxy and $p$-substituted phenoxy derivatives $(S)$-enantiopreference was observed, $99 \%$ yield of conversion was achieved with ee> 98 and $87 \%$ respectively. In the case of 33 the $(R)$-product of reduction was obtained with ee $>99 \%$ but with a yield of $68 \%$. The hydrogen attack was performed by the $R e$-face in case of $\mathbf{3 2}$ and by the $S i$-face in the case of 33. The same stereobias was described for ADH from $S$. cerevisiae type II and $Y$. lipolytica. These results were related to the different electronic properties and dipolar moments of $\mathbf{3 2}$ and $\mathbf{3 3}$ according to the molecular orbital calculations that could favour the different recognition of each molecule by the active site [55].

Immobilized biocatalysts techniques are newly developed methods for organic syntheses. Sinisterra described the two most active yeast strains that were chosen for immobilization in calcium alginate [56]. The cells were immobilized using the gel entrapment technique. The maximum productivity of alcohol dehydrogenases was achieved at the beginning of the stationary phase for $Y$. lipolytica (48h) and during the logarithmic phase for $P$. mexicana (12h). The immobilization reduced the enzymatic activity of $P$. mexicana from $77 \%$ to $38 \%$ (the reduction of cyclohexanone to cyclohexanol was considered as the reaction test). The same was observed in the case of $S$. cerevisiae Sigma Type II. These results could be related to an increase in the microenvironmental concentration of hydrophobic toxic molecules (cyclohexanol and cyclohexanone). On the contrary, the reduction activity of $Y$. lipolytica was not relevantly altered by immobilization, which confirms the great resistance of this strain to toxic hydrophobic molecules. The immobilized biocatalysts can be reused at least five times in the reduction of ketones. What is interesting is that the authors reported the formation of $(R)$-halohydrine $\mathbf{8}$ from haloketone $\mathbf{3 2}$ by immobilization of the resting cells of $P$. mexicana and $Y$. lipolytica with high yields $(75-85 \%)$ and ee $(95-97 \%)$. This study indicated the convenience of the immobilization of whole cells to perform the process. After five cycles - equivalents $240 \mathrm{~h}$ of work the biocatalyst retained about $50 \%$ of its original activity, retaining at the same time the enantioselectivity. 


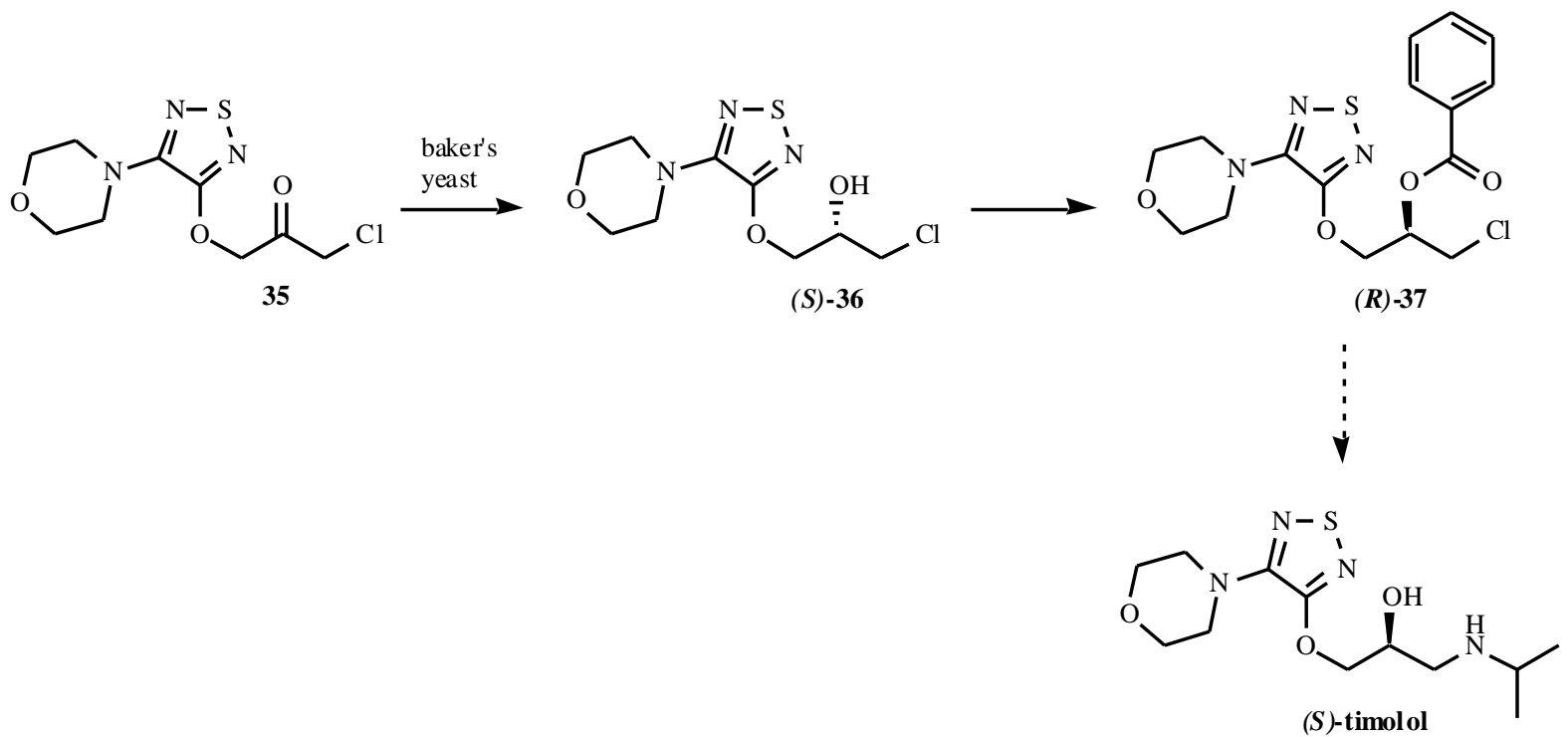

Fig. (14). Chemoenzymatic route for the synthesis of (S)-timolol.

More important, the procedure of isolation of products is less complicated and time consuming in the case of immobilized cells compared to fresh ones.

Biocatalytic asymmetric synthesis of $(S)$ - and $(R)$-timolol was presented by Prati [57] Fig. (14). Asymmetric reduction of the prochiral haloketone $\mathbf{3 5}$ was performed by baker's yeasts. The reductions were carried out with modifications of conditions in order to improve stereoselectivity. Resting cells showed complete conversion in a short period of time. Moreover, an easy and highly effective recovery of the reduction product was reported under these conditions. The optimal ee value (87\%) and a convenient yield (67\%) were obtained when the ratio yeast: substrate was $30(\mathrm{~g} / \mathrm{mM})$, with the portion-wise addition of haloketone $\mathbf{3 5}$ and in the presence of allyl alcohol. Mitsunobu procedure for the inversion of the stereochemistry of $\mathbf{3 6}$ was applied in order to synthesize (S)-timolol. The optical purity of both enantiomers of timolol was at the same level $87 \%$.

\section{OTHER METHODS}

Among other enzymes with a great potential for the asymmetric synthesis of chiral $\beta$-blockers, epoxidases and epoxide hydrolases should be mentioned. An interesting route for obtaining optically pure $\beta$-blockers is via stereoselective microbial epoxidation of aryl allyl ethers $\mathbf{3 8}$ to give (S)-aryl glycidyl ethers 4 Fig. (15), which are common precursors for the synthesis of most $\beta$-blockers according to the described standard procedures [58]. It was applied in the synthesis of $(S)$-metoprolol and $(S)$-atenolol from prochiral allyl ethers in reaction of epoxidation by alkene-utilizing bacteria Pseudomonas oleovorans with an excellent enantioselectivity (ee $98 \%$ and $97 \%$ respectively) [59].

Mahmoudian screened eighteen newly isolated etheneand propene-utilizing bacteria for the ability to produce optically pure $(S)$-phenyl glycidyl ether $(4)(\mathrm{R}=\mathrm{H})$ [60]. The most promising strains Micrococcus sp. M90C and two other ethene-utilizing bacteria - M26 and M93A - gave high ee values around $93 \%$ and high conversion yields (85-89\%).
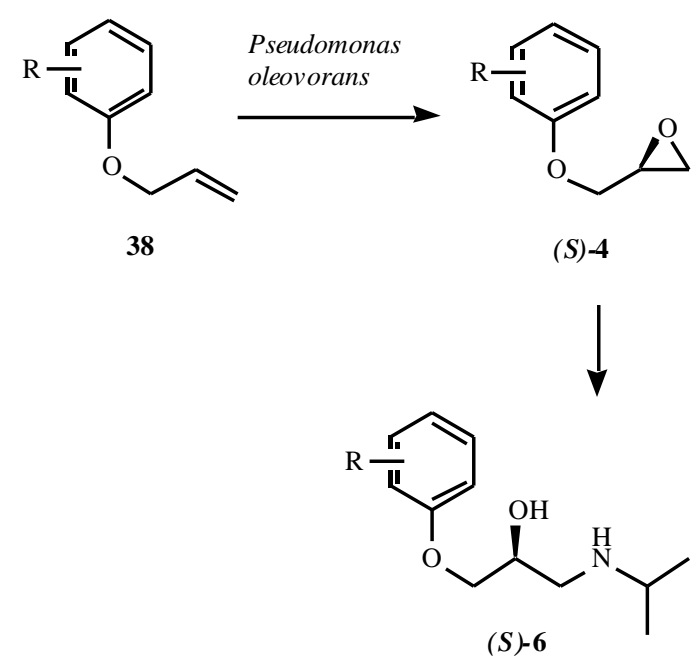

Fig. (15). Epoxidation of aryl allyl ethers.

A surprising biodegradation study for the preparation of propranolol and atenolol was presented in 2000 [61]. This process using whole cells is economical and operationally simple. The above mentioned chemicals or their $O$-acetates, were incubated with Rhizopus arrhizus or Geotrichum candidum. The different $\mathrm{pH}$ conditions and varying time intervals were applied to check the stereoselectivity of sorption. It was observed that $(R)$-propranolol and $(R)$ atenolol (as well as their acetates) were metabolised first, resulting in the recovery of $(S)$-isomers. This method described asymmetric destruction of $\beta$-blockers distomers with $88-99 \%$ ee (the latter concerns atenolol) during the time of 6 days. Additionally, the authors concluded that biodegradation of drugs mentioned above is a better method than biodegradation of corresponding esters.

\section{RECENT ADVANCES AND PROSPECTIVES}

This review has shown that many microorganisms and isolated enzymes can be used in the chemo-enzymatic synthesis of optically active $\beta$-adrenergic blocking agents. 
Enzymes are useful for the production of chiral molecules owing to their exquisite regio- and stereospecificity. Main targets for optimization of enzymes are improving their stereoselectivity, activity, productivity and stability under process conditions [62]. Activity and stereoselectivity can be modified either by chemical modification, immobilization or solvent engineering. More recent approaches are the application of repeated rounds of random mutagenesis, in vitro recombination (DNA shuffling) and selection to develop enzymes with improved properties, more commonly referred to as directed evolution.

Directed evolution was applied to enhance the substrate selectivity of esterase from Pseudomonas fluorescens for hydrolytic activity toward a sterically hindered 3hydroxyester, which is useful in the synthesis of propranolol. In opposition to non-active parent enzyme, an active mutant enzyme hydrolyzed the above mentioned ester and resulted in an upgrade of the ee ratio [63]. The directed evolution was also used for improving the enantioselectivity of epoxide hydrolase from Agrobacterium radiobacter. Chiral epoxides, particularly phenyl glycidyl ethers and epichlorohydrines are potent building blocks for the preparation of $\beta$-adrenergic ligands. After error-prone PCR and recombination of the beneficial mutations by DNA shuffling, the obtained mutants possessed 2-20 fold improved enantioselectivity (expressed as an E value) in comparison to the wilde type epoxide hydrolase [64]. The stereoselectivities of baker's yeast catalyzed reductions of $\beta$ keto esters can be manipulated genetically as well. Strains have been constructed in which two major reductases were either knocked out or overexpressed. The recombinant strains were constructed to provide useful biocatalysts for substrates that are reduced with poor and moderate enantioselectivity by unmodified baker's yeast [65].

\section{ABBREVIATIONS}

$\begin{array}{ll}\mathrm{ADH} & =\text { Alcohol dehydrogenase } \\ \mathrm{CAL} & =\text { Candida antarctica lipase } \\ \mathrm{CAL} A+\mathrm{B} & =\text { Candida antarctica lipases A+B } \\ \mathrm{CALB} & =\text { Candida antarctica lipase B } \\ \mathrm{CCL} & =\text { Candida cylindracea lipase } \\ \mathrm{CRL} & =\text { Candida rugosa lipase } \\ \mathrm{CVL} & =\text { Chromobacterium viscosum lipase } \\ \mathrm{DIPE} & =\text { Diisopropyl ether } \\ \mathrm{DKR} & =\text { Dynamic kinetic resolution } \\ \mathrm{E} & =\text { Enantiomeric ratio } \\ \text { ee } & =\text { Enantiomeric excess } \\ \text { ee } & =\text { Enantiomeric excess of a product } \\ \text { ee } & =\text { Enantiomeric excess of a substrate } \\ \text { logP } & =\text { Logarithm of the octanol-water partition } \\ \mathrm{LPL} & =\text { Lipoprotein lipase from Pseudomonas sp } \\ \mathrm{LPSA} & =\text { Lipase Pseudomonas Amano }\end{array}$

$\begin{array}{ll}\text { MJL } & =\text { Mucor javanicus lipase } \\ \text { PAF } & =\text { Platelet activating factor } \\ \text { PCL } & \text { Pseudomonas cepacia lipase } \\ \text { PEG-DNCP } & =\text { PEG dinitrophenylcarbonate } \\ \text { PLAP } & =\text { Pig liver acetone powder } \\ \text { PPL } & =\text { Porcine pancreatic lipase } \\ \text { PS-C } & =\text { Pseudomonas cepaciae lipase immobilized } \\ & \text { on modified ceramic particles } \\ \text { PS-D } & \text { Pseudomonas cepaciae lipase immobilized } \\ \text { PSL } & =\text { lipase PS } \\ \text { TTCHD-D } & =1,5,9,13 \text {-tetrathiacyclohexadecane-3,11-diol } \\ \text { VA } & =\text { Vinyl acetate }\end{array}$

\section{REFERENCES}

[1] Hoffman, B.B. In Basic and Clinical Pharmacology, Katzung, B.G, Ed.; Appleton and Lange, Stamford, 1998, pp. 136-151.

[2] www.rxlist.com

[3] Waldo, A.L.; Camm, A.J.; de Ruyter, H.; Friedman, P.L.; MacNeil, D.J.; Pauls, J.F.; Pitt, B.; Pratt, C.M.; Schwartz, P.J.; Veltri, E.P. Lancet, 1996, 348, 7.

[4] Stoschitzky, K.; Lindner, W.; Zernig G. J. Clin. Bas. Cardiol., 1998, $1,15$.

[5] Mehvar, R.; Brocks, D.R. J. Pharm. Pharmaceut. Sci., 2001, 4, 185.

[6] Davis, H.G. Biotransformations in Preparative Organic Chemistry; the use of isolated enzymes and whole cell systems in synthesis, Academic Press: London, 1989.

[7] Faber, K. Biotransformation in Organic Chemistry: a textbook, Springer: Berlin, 1997

[8] Straathof, A.J.J.; Panke, S.; Schmid, A. Curr. Opin. Biotech., 2002 13,548 .

[9] Laumen, K.; Kittelmann, M.; Ghisalba, O. J. Mol. Catal. B: Enzym., 2002, 19-20, 55.

[10] Patel, R. N. Enzyme Microb. Technol., 2002, 31, 804.

[11] Kloosterman, M.; Elferink, V.H.M.; Iersel, J.; Roskam, J.-H.; Meijer, E.M.; Hulshof, L.A.; Sheldon, R.A. Trends Biotechnol. TIBTECH, 1988, 6, 251.

[12] Margolin, A.L. Enzyme Microb. Technol., 1993, 15, 266.

[13] Bornscheuer, U.T.; Kazlauskas, R.J. Hydrolases in Organic Synthesis - Regio- and Stereoselective Biotransformations, WileyVCH: Weinheim, 1999.

[14] Schmid, R.D.; Verger, R. Angew. Chem. Int. Ed. Eng., 1998, 37, 1608.

[15] Kirschner, G.; Scollar, M.P.; Klibanov, A.M. J. Am. Chem. Soc., 1985, 107, 7072 .

[16] Shieh, W.-R.; Gou, D.-M.; Chen, C.-S. J. Chem. Soc., Chem. Commun., 1991, 651.

[17] Chen, C.S.; Fujimoto, Y.; Gridaukas, G.; Sih, C.J. J. Am. Chem. Soc., 1982, 104, 7294.

[18] Kamal, A.; Damayanthi, Y.; Rao, M.V. Tetrahedron: Asymmetry, 1992, 3, 1361.

[19] Chiou, T.-W.; Chang, C.-C.; Lai, C.-T.; Tai, D.-F. Bioorg. Med. Chem. Lett., 1997, 7, 433.

[20] Hsu, S.-H.; Wu, S.-S; Wang, Y.-F. Tetrahedron Lett., 1990, 31, 6403.

[21] Bevinakatti, H.S.; Banerji, A.A. J. Org. Chem., 1991, 56, 5372.

[22] Bevinakatti, H.S.; Banerji, A.A. J. Org. Chem., 1992, 57, 6003.

[23] Thakkar, N.V.; Banerji, A.A.; Bevinakatti, H.S. Biotechnol. Lett., 1995, 17, 217.

[24] Ader, U.; Schneider, M.P. Tetrahedron: Asymmetry, 1992, 3, 201.

[25] Ader, U.; Schneider, M.P. Tetrahedron: Asymmetry, 1992, 3, 205.

[26] Ader, U.; Schneider, M.P. Tetrahedron: Asymmetry, 1992, 3, 521.

[27] Bermudez, J.L.; del Campo, C.; Salazar, L.; Llama, E.F.; Sinisterra, J.V. Tetrahedron: Asymmetry, 1996, 7, 2485. 
[28] Coleman, A.J.; Paterson, D.S.; Somerville, A.R. Biochem. Pharmacol., 1979, 28, 1011.

[29] Kaimal, T.N.B.; Prasad, R.B.N.; Chandrasekhara Rao, T. Biotechnol. Lett., 1992, 14, 21.

[30] Raju, S.B.; Chiou, T.-W.; Tai, D.-F. Tetrahedron: Asymmetry, 1995, 6,1519 .

[31] Mohapatra, S.C.; Hsu, J.T. Biotechnol. Bioeng., 1997, 55, 399.

[32] Mohapatra, S.C.; Hsu, J.T. Biotechnol. Bioeng., 1999, 64, 213.

[33] Kapoor, M.; Anand, N.; Koul, S.; Chimni, S.S.; Manhas, K.S.; Raina, C.; Parshad, R.; Taneja, S.C.; Qazi, G.N. Bioorg. Chem. 2003, 31, 259 .

[34] Kazlauskas, R.J.; Weissfloch, A.N.E.; Rappaport, A.T.; Cuccia, L.A. J. Org. Chem., 1991, 56, 2656.

[35] Di Nunno, L.; Franchini, C.; Scilimati, A.; Sinicropi, M.S. Tortorella, P. Tetrahedron: Asymmetry, 2000, 11, 1571.

[36] Iriuchijima, S.; Kojima, N. Agric. Biol. Chem., 1982, 46, 1153.

[37] Terao, Y.; Murata, M.; Achiwa, K.; Nischio, T.; Akamtsu, M. Kamimura, M. Tetrahedron Lett., 1988, 29, 5173

[38] Theil, F.; Lemke, K.; Ballschuh, S.; Kunath, A.; Schick, H. Tetrahedron: Asymmetry, 1995, 6, 1323.

[39] Salazar, L.; Bermudez, J.L.; Ramirez, C.; Llama, E.F.; Sinisterra, J.V. Tetrahedron: Asymmetry, 1999, 10, 3507.

[40] Dallanoce, C.; De Amici, M.; Carrea, G.; Secundo, F.; Castellano, S.; De Micheli, C. Tetrahedron: Asymmetry, 2000, 11, 2741.

[41] Bornscheuer, U.; Herar, A.; Kreye, L.; Wendel, V.; Capewell, A.; Meyer, H.H.; Scheper, T.; Kolisis, F.N. Tetrahedron: Asymmetry, 1993, 4, 1007.

[42] Wünsche, K.; Schwaneberg, U.; Bornscheuer, U.T., Hartmut, H.M. Tetrahedron: Asymmetry, 1996, 7, 2017.

[43] Pchelka, B.K.; Loupy, A.; .Plenkiewicz, J.; Blanco, L. Tetrahedron: Asymmetry, 2000, 11, 2719

[44] Pàmiés, O.; Bäckvall, J.-E. J. Org. Chem., 2001, 66, 4022

[45] Matsuo, N.; Ohno, N. Tetrahedron Lett., 1985, 26, 5533.

[46] Wang, Y.-F.; Chen, S.-T.; Liu, K.K.-C.; Wong, C.-H. Tetrahedron Lett., 1989, 30, 1917.

[47] Kamal, A.; Khanna, G.B.R.; Krishnaji, T.; Tekumalla, V.; Ramu, R. Tetrahedron: Asymmetry, 2005, 16, 1485.
[48] Nakamura, K.; Kawai, Y.; Nakajima, N.; Ohno, A. J. Org. Chem., 1991, 56, 4778 .

[49] Egri, G.; Kolbert, A.; Bálint, J.; Fogassy, E.; Novák, L.; Poppe, L. Tetrahedron: Asymmetry, 1998, 9, 271.

[50] Martinez, F.; del Campo, C.; Sinisterra, J.V.; Llama, E.F. Tetrahedron: Asymmetry, 2000, 11, 4651.

[51] Nakamura, K. J. Mol. Catal. B. Enzym., 1998, 5, 129.

[52] Martinez-Lagos, F.; Carballeira, J.D.; Bermúdez, J.L.; Alvarez, E.; Sinisterra, J.V. Tetrahedron: Asymmetry, 2004, 15, 763

[53] Carballeira, J.D. PhD Thesis, Universidad Complutense, Madrid, July, 2003.

[54] Martinez-Lagos, F., del Campo, C.; Llama, E.F.; Sinisterra, J.V. Enzyme Microbial. Technol., 2002, 30, 895.

[55] Carballeira, J.D.; Álvarez, E.; Campillo, M.; Pardo, E.; Sinisterra, J.V. Tetrahedron: Asymmetry, 2004, 15, 951.

[56] Martinez Lagos, F.; Sinisterra, J.V. J. Mol. Catal. B: Enzym., $\mathbf{2 0 0 5}, 36,1$

[57] Tosi, G.; Zironi, F.; Caselli, E.; Forni, A.; Prati, F. Synthesis, 2004, 10,1625

[58] Kleemann, A.; Engel, J.; Kutscher, B.; Reichert, D Pharmaceutical substances, 3-rd edition. Syntheses, Patents, Applications, Thieme: Stuttgart, 1999.

[59] Johnstone, S.L.; Philips, G.T.; Robertson, B.W.; Watts, P.D.; Bertola, M.A.; Koger, H.S.; Marx, A.F. In Biocatalysis in Organic Media, Laane, C.; Tramper, J.; Lilly, M.D., Ed.; Elsevier: Amsterdam, 1987; pp. 387-392.

[60] Mahmoudian, M.; Michael, A. Appl. Microbiol. Biotechnol., 1992 37, 28.

[61] Damle, S.V.; Patil, P.N.; Salunkhe, M.M. Bioorg. Med. Chem., 2000, 8, 2067.

[62] Chartrain, M.; Salmon, P.M.; Robinson, D.K.; Buckland, B.C. Curr Opin. Biotechnol., 2000, 11, 209.

[63] Bornscheuer U.T.; Altenbuchner, J.; Meyer, H.H. Biotechnol. Bioeng., 1998, 58, 554.

[64] van Loo, B.; Spelberg, J.H.L.; Kingma, J.; Sonke, T.; Wubbolts, M.G.; Janssen, D.B. Chem. Biol., 2004, 11, 981

[65] Rodriguez, S.; Kayser, M.; Stewart, J.D. Org. Lett., 1999, 1, 1153. 